\title{
Crizotinib in patients with anaplastic lymphoma kinase-positive advanced non-small cell lung cancer versus chemotherapy as a first-line treatment
}

Jianya Zhou ${ }^{1 *}$, Jing Zheng ${ }^{1}$, Xiaochen Zhang ${ }^{2}$, Jing Zhao ${ }^{3}$, Yanping Zhu' ${ }^{1}$, Qian Shen ${ }^{1}$, Yuehong Wang ${ }^{1}$, Ke Sun ${ }^{3}$, Zeying Zhang ${ }^{1}$, Zhijie Pan ${ }^{1}$, Yihong Shen ${ }^{1}$ and Jianying Zhou ${ }^{1 *}$

\begin{abstract}
Background: To compare the efficacy of crizotinib, pemetrexed and other chemotherapy regimens as a first-line treatment in patients with anaplastic lymphoma kinase (ALK)-positive non-small cell lung cancer (NSCLC) in real world clinical use and to evaluate the $+86-571-87,236,876$ predictive clinical factors of the efficacy of crizotinib.

Methods: The 73 patients with ALK-positive advanced NSCLC were divided into three groups based on the first-line treatment: first-line crizotinib group (1-CRZ group, $n=32$ ); first-line platinum-based pemetrexed treatment group (1-PP group, $n=28$ ), and first-line chemotherapy platinum-based non-pemetrexed group (N1-PP, $n=12$ ). Sixty eight of the 73 patients received crizotinib treatment and followed up in our hospital. Differences in the objective response rate (ORR), disease control rate (DCR) and progression-free survival (PFS) were compared in the different groups. The clinical factors were evaluated to predict the efficacy of crizotinib by the Kaplan-Meier survival analysis and Cox proportional hazards model.

Results: The PFS, ORR, DCR were 16.1 months, 78.1\% (25/32) and 100\% (32/32) in the 1-CRZ group; were 6.0 months, $17.9 \%(5 / 28)$ and $57.2 \%(16 / 28)$ in the 1-PP group; and were 2.9 months, $15.4 \%(2 / 13)$ and $46.2 \%(6 / 13)$ in the N1-PP group. The PFS of the 1-CRZ group was significantly longer than that of the 1-PP group $(P<0.001)$ and the N1-PP group $(P<0.001)$. The ORR and DCR of the $1-C R Z$ group was significantly greater than that of the 1-PP group and the N1-PP group (all the $P<0.001$ ). Higher Eastern Cooperative Oncology Group (ECOG) performance status score $(>=2)$ ( $\mathrm{HR} 2.345,95 \% \mathrm{Cl} 1.137-4.834, P=0.021)$ and patients received crizotinib after N1-PP chemotherapy (HR 2.345, 95\% Cl $1.137-4.834, \mathrm{P}=0.021$ ) were two factors associated with shorter PFS after crizotinib treatment.

Conclusions: In patients with ALK-positive NSCLC who did not receive previous treatment, crizotinib was superior to standard chemotherapy for the longer PFS and greater ORR and DCR. Higher ECOG score $(>=2)$ and patients received crizotinib after N1-PP chemotherapy predict poor efficacy of crizotinib.
\end{abstract}

Keywords: Crizotinib, ALK, Non-small cell lung cancer, Efficacy, Pemetrexed

\footnotetext{
* Correspondence: zhoujy@zju.edu.cn; zjyhz@zju.edu.cn

${ }^{1}$ Department of Respiratory Disease, Thoracic Disease Center, The First

Affiliated Hospital, College of Medicine, Zhejiang University, No. 79,

Qingchun Road, Xiacheng District, Hangzhou, China

Full list of author information is available at the end of the article
}

(c) The Author(s). 2018 Open Access This article is distributed under the terms of the Creative Commons Attribution 4.0 International License (http://creativecommons.org/licenses/by/4.0/), which permits unrestricted use, distribution, and reproduction in any medium, provided you give appropriate credit to the original author(s) and the source, provide a link to the Creative Commons license, and indicate if changes were made. The Creative Commons Public Domain Dedication waiver (http://creativecommons.org/publicdomain/zero/1.0/) applies to the data made available in this article, unless otherwise stated. 


\section{Background}

Lung cancer is the leading cause of cancer-related death worldwide with an estimated 1.4 million deaths per year [1]. Traditionally, lung cancer has been histologically divided into non-small cell lung cancer (NSCLC) and small cell lung cancer. Approximately $85-90 \%$ of all lung cancer cases are carcinomas of NSCLC $[1,2]$. The development of epidermal growth factor receptor (EGFR)-targeted tyrosine kinase inhibitors (TKI) led to a different molecular pathology classification in terms of targeted therapies for lung cancer.

In 2007, the echinoderm microtubule-associated protein-like 4-anaplastic lymphoma kinase (EML4-ALK) rearrangement was discovered in NSCLC. Overall, $A L K$ rearrangements are found in approximately $3 \%$ to $7 \%$ of patients with NSCLC but have been identified primarily in lung adenocarcinomas and are more frequently found in younger patients and in never or light smokers [3-6].

$A L K$ rearrangements in NSCLC were associated with prolonged progression-free survival (PFS) of patients who received pemetrexed-based chemotherapy before the discovery of crizotinib, a targeted ALK tyrosine kinase inhibitor [7, 8]. Crizotinib is an oral multitargeted inhibitor of receptor tyrosine kinases including ALK, tyrosine-protein kinase Met (c-Met, also known as hepatocyte growth factor receptor, HGFR), and Recepteur d'Origine Nantais (RON, also known as Macrophagestimulating protein receptor, MST1R) $[9,10]$. Crizotinib has demonstrated concentration-dependent inhibition of ALK and c-Met phosphorylation in cell-based assays of tumour cell lines and has also demonstrated antitumor activity in mice with tumour xenografts that express ALK fusion proteins or c-Met $[10,11]$. The antitumour efficacy of crizotinib was confirmed in several clinical trials for patients with advanced cancers with ALK rearrangements who either were or were not treated as a first-line therapy [11-13]. Not only was the tumour assessment-based outcome improved but the patientreported outcome (PRO) was also improved in patients who were enrolled in these clinical trials. The dramatic effectiveness [11-14] and the tolerable side effects [14-16] observed in these clinical trials were the impetus for accelerated approval of crizotinib by the US Food and Drug Administration in 2011.

Approval of crizotinib by the China Food and Drug Adiministration was given in Jan 2013. Although some Chinese patients bought crizotinib from overseas before the approval, many more Chinese patients with advanced ALK-positive lung cancer received crizotinib treatment after its approval. We observed 73 patients with advanced ALK-positive lung cancer who underwent different treatment strategies, and $93.2 \%(68 / 73)$ of the patients received crizotinib treatment. Here, we compare the efficacy of crizotinib, pemetrexed and other chemotherapy regimens as a first line treatment of Chinese patients with ALKpositive NSCLC and evaluate the impact of first line therapy (pemetrexed or not-pemetrexed), brain metastasis (BM) before crizotinib treatment, ECOG score etc. on the PFS of crizotinib treatment by the Kaplan-Meier survival analysis and Cox proportional hazards model in a real world.

\section{Methods}

\section{Patient selection and grouping}

Approval for this study was obtained by Ethics Committee of the first affiliated hospital of Zhejiang University and the ethics committee waived the use of the inform consent. All 73 patients met the following conditions: 1. ALK gene rearrangements in tumour biopsies obtained from these patients were confirmed by fluorescence in situ hybridization (FISH) using the Vysis ALK break-apart probe set (Abbott Laboratories, Abbott Park, IL, USA). Positive cells were defined as: red and green signals that were separated by $\geq 2$ signal diameters or deleted 5'ALK green signal observed in tumour cell nuclei. FISHpositive cases were classified as a more than $15 \%$ percentage of the total positive cells [17]; 2 . When the patients were diagnosed, TNM staging was determined to be IIIB or IV according to the seventh edition of the Union for International Cancer Control and American Joint Committee on Lung Cancer TNM classification. 3. The time from diagnosis to the cut-off date of our study (31-OCT-2016) was at least one year. 4. All patients received chemotherapy or crizotinib treatment and were followed-up in our hospital.

\section{Patient grouping}

According to their treatment history retrospectively obtained from the medical record, all patients were divided into three groups according to first-line treatment: first-line crizotinib group (1-CRZ group, $n=32$ ); first-line platinum-based pemetrexed treatment group (1-PP group, $n=28$ ); first-line chemotherapy platinum-based non-pemetrexed group (N1-PP, $n=13)$.

\section{Data collection}

All patients were followed-up from the day when ALK rearrangement was confirmed until 31-OCT-2016. The interval systemic imaging (computed tomography [CT] or positron emission tomography/CT [PET/CT]) were obtained at the physician's discretion for tumour assessment. Tumour assessment was performed according to the Response Evaluation Criteria in Solid Tumors 1.1. The baseline epidemiological data, gender, age, smoking history, Eastern Cooperative Oncology Group (ECOG) performance status score, extent of disease, treatment history, and response to therapy were retrospectively 
extracted from the medical record of each patient retrospectively.

The objective response rate (ORR) was defined as the sum of the rates of disease partial responses (PR) plus complete responses (CR). The disease control rate (DCR) was defined as the sum of the rates of PR, CR and stable disease (SD). Both the ORR and the DCR were calculated in our study. Progression-free survival (PFS) was defined as the time from the treatment with crizotinib or chemotherapy to progressive disease (PD) or death.

\section{Statistical analysis}

Differences in the categorical data, such as smoking history, ECOG score, ORR and DCR among the different groups were compared using the Chi-Square test. The differences in age were compared by the Kruskal-Wallis test. The Kaplan-Meier method was used to estimate PFS and the difference of different groups were compared by using log-rank test. Covariates with a $P \leq 0.10$ in univariate analysis were included in the multivariate model. Multivariate analysis was performed by using the Cox proportional hazards model.

\section{Results}

\section{Demographics}

All 73 patients were diagnosed with unresectable advanced ALK-positive lung cancer and were treated in our hospital. The mean follow-up was 30.2 months (range: 12-57 months). Among all the 73 patients, 68 patients received crizotinib therapy as first-line or not first line treatment. Three patients were excluded for the
PFS data was not evaluable (NE) and the other 65 patients included 31 patients from the 1-CRZ group, 22 patients from 1-PP group and 12 patients from N1-PP group.

In all, $50.7 \%(37 / 73)$ of the patients were female, and only $32.9 \%(24 / 73)$ of the patients were current or former smokers; the mean age of the patients was 51.4 (range: 23-73) years old. The baseline epidemiological characteristics at the time of diagnosis including gender, smoking history, ECOG score, and extent of disease were similar among patients in the 1-PP, N1-PP and 1-CRZ groups (Table 1). Patients in the N1-PP group were younger than the other two groups $(P=0.045)$. In addition, the difference of the epidemiological characteristics except for ECOG score at the time of crizotinib treatment among patients from different groups was also not significant (Table 2). 33.3\% (4/12) patients from N1-PP group had $\geq 2$ ECOG score, which was more than patients from 1-CRZ group (6.5\%, $P=0.042)$ and similar with patients from 1-PP group $(18.2 \%, P=0.410)$.

\section{Comparison of the efficacy of different first-line treatments based on a tumour assessment}

Until the cut-off date, one patient lost contact after PR in 1-CRZ group and the PFS data was not evaluable (NE); in the 1-PP group, 3 patients withdrawal chemotherapy for the side-effects and the response and PFS was NE, 2 patients asked for crizotinib treatment despite SD after chemotherapy and the PFS data was NE; one patients withdrawal chemotherapy for the side-effects and the response and PFS was NE in the N1-PP group.

Table 1 Comparison of the baseline epidemiological characteristics of the different groups

\begin{tabular}{|c|c|c|c|c|c|}
\hline \multirow[t]{2}{*}{ Characteristics } & \multicolumn{4}{|l|}{ Group } & \multirow[t]{2}{*}{$P$ value } \\
\hline & Total & $1-C R Z$ & $1-P P$ & N1-PP & \\
\hline Total, n & 73 & 32 & 28 & 13 & \\
\hline \multicolumn{6}{|l|}{ Gender, n (\%) } \\
\hline Male & $36(49.3)$ & $19(59.4)$ & $11(39.3)$ & $6(46.2)$ & \multirow[t]{2}{*}{0.290} \\
\hline Female & $37(50.7)$ & $13(40.6)$ & $17(60.7)$ & $7(53.8)$ & \\
\hline Median age, year (range) & $51.4(23-73)$ & $53.3(30-73)$ & $49.6(23-71)$ & $43.2(23-61)$ & 0.045 \\
\hline \multicolumn{6}{|l|}{ Smoking, n (\%) } \\
\hline Never & $49(67.1)$ & 19(59.4) & $21(75.0)$ & $9(69.2)$ & \multirow[t]{2}{*}{0.431} \\
\hline Current/Former & $24(32.9)$ & $13(40.6)$ & $7(25.0)$ & $4(30.8)$ & \\
\hline \multicolumn{6}{|l|}{ ECOG score, n (\%) } \\
\hline 0 or 1 & $69(94.5)$ & $30(93.8)$ & $26(92.9)$ & $13(100.0)$ & \multirow[t]{2}{*}{0.625} \\
\hline$>=2$ & $4(5.5)$ & $2(6.2)$ & $2(7.1)$ & $0(0)$ & \\
\hline \multicolumn{6}{|l|}{ Extent of disease, n (\%) } \\
\hline Locally advanced & $14(19.2)$ & $6(18.8)$ & $5(17.9)$ & $3(23.1)$ & \multirow[t]{2}{*}{0.922} \\
\hline Metastatic & $59(80.8)$ & $26(81.2)$ & $23(82.1)$ & $10(76.9)$ & \\
\hline
\end{tabular}

Note. - Unless otherwise indicated, the data are shown as numbers with percentages in parentheses. The statistical analysis for age was performed using the Mann-Whitney test. The statistical analyses for other clinical features were performed using the Chi-Square test 
Table 2 Comparison of the epidemiological characteristics for patients received crizotinib treatment

\begin{tabular}{|c|c|c|c|c|c|}
\hline \multirow[t]{2}{*}{ Characteristics } & \multicolumn{4}{|l|}{ Group } & \multirow[t]{2}{*}{$P$ value } \\
\hline & Total & $1-C R Z$ & $1-\mathrm{PP}$ & N1-PP & \\
\hline Total, n & 65 & 31 & 22 & 12 & \\
\hline \multicolumn{6}{|l|}{ Gender, n (\%) } \\
\hline Male & $31(47.7)$ & $18(58.1)$ & $8(36.4)$ & $5(41.7)$ & \multirow[t]{2}{*}{0.267} \\
\hline Female & $34(52.3)$ & $13(41.9)$ & $14(63.6)$ & $7(58.3)$ & \\
\hline Median age, year (range) & $50.2(23-73)$ & $50.9(30-73)$ & $51.9(23-71)$ & $42.5(23-61)$ & 0.640 \\
\hline \multicolumn{6}{|l|}{ Smoking, n (\%) } \\
\hline Never & $44(67.7)$ & $19(61.3)$ & $17(77.3)$ & $8(66.7)$ & \multirow[t]{2}{*}{0.470} \\
\hline Current/Former & $21(32.3)$ & $12(38.7)$ & $5(22.7)$ & $4(33.3)$ & \\
\hline \multicolumn{6}{|l|}{ ECOG score, n (\%) } \\
\hline 0 or 1 & $55(84.6)$ & $29(93.5)$ & $18(81.8)$ & $8(66.7)$ & \multirow[t]{2}{*}{0.035} \\
\hline$>=2$ & $10(15.4)$ & $2(6.5)$ & $4(18.2)$ & $4(33.3)$ & \\
\hline \multicolumn{6}{|l|}{ Extent of disease, n (\%) } \\
\hline Locally advanced & $10(15.4)$ & $5(16.1)$ & $3(13.6)$ & $2(16.7)$ & \multirow[t]{2}{*}{0.961} \\
\hline Metastatic & 55 (84.6) & $26(83.9)$ & $19(86.4)$ & $10(83.3)$ & \\
\hline
\end{tabular}

Note. - Unless otherwise indicated, the data are shown as numbers with percentages in parentheses. The statistical analysis for age was performed using the Mann-Whitney test. The statistical analyses for other clinical features were performed using the Chi-Square test

The response to first line crizotinib/chemotherapy is shown in Table 3. In the 1-CRZ group, the ORR and DCR were $78.1 \%(25 / 32)$ and $100 \%(32 / 32)$; in the 1 -PP group, the ORR and DCR were $17.9 \%(5 / 28)$ and $57.2 \%$ (16/28); the ORR and DCR were $15.4 \%(2 / 13)$ and $46.2 \%$ $(6 / 13)$ in the N1-PP group. The ORR of patients in the 1-CRZ group was significantly greater than that of patients in the 1-PP group $(P<0.001)$ and the N1-PP group $(P<0.001)$. The DCR of patients in the $1-C R Z$ group was significantly greater than that of patients in the 1-PP group $(P<0.001)$ and N1-PP group $(\mathrm{P}<0.001)$. Both the ORR and DCR were similar between the 1-PP group and the N1-PP group $(P=1.000$, 0.737 , respectively).

The PFS of the patients in the 1-CRZ group $(n=31)$, 1-PP group $(n=23)$, and N1-PP group $(n=12)$ is shown in Fig. 1. The median PFS of the patients in the three groups was 16.1 months (95\% confidence interval [CI], 12.7 to 19.4$), 6.0$ months $(95 \% \mathrm{CI}, 3.6$ to 8.4$)$, and 2.9 months (95\% CI, 1.6 to 4.1 ), respectively. The PFS of patients in the 1-CRZ group was significantly longer than that of patients in the 1-PP group $(\mathrm{P}<0.001)$ and the N1-PP group $(\mathrm{P}<0.001)$. The PFS of patients in the 1-PP group was not significantly longer than that of the patients in the N1-PP group $(P=0.056)$.

Overall survival (OS) calculations were incomplete for only $28.8 \%$ (21/73) patients in our study had died by the cut-off date.

\section{Impact of first line therapy on the PFS of crizotinib treatment}

The PFS after crizotinib treatment among patients from different groups were shown in Fig. 2. The PFS of patients from the 1-CRZ group (16.1 months, 95\%CI, 12.7

Table 3 Efficacy comparison of different first-line treatments based on a tumour assessment

\begin{tabular}{llll}
\hline Tumour assessment & \multicolumn{1}{l}{ First-line treatment } & N1-PP( $(\mathrm{n}=13)$ \\
\cline { 2 - 4 } Type of response, $\mathrm{n} \%$ & $1-\mathrm{CRZ}(\mathrm{n}=32)$ & $1-\mathrm{PP}(\mathrm{n}=28)$ & $\mathrm{P}$ value \\
Complete response & $1(3.1)$ & $0(0)$ & $2(15.4)$ \\
Partial response & $24(75.0)$ & $5(17.9)$ & $4(30.8)$ \\
Stable disease & $7(21.9)$ & $11(39.3)$ & $6(46.1)$ \\
Progressive disease & $0(0)$ & $9(32.1)$ & $1(7.7)$ \\
Not evaluable & $0(0)$ & $3(10.7)$ & 15.4 \\
ORR(\%) & 78.1 & 17.9 & 46.2 \\
DCR(\%) & 100.0 & 57.2 & $<0.001$ \\
\hline
\end{tabular}

Note. - Unless otherwise indicated, the data are shown as numbers with percentages in parentheses. The statistical analysis for DCR and ORR were performed using the Chi-Square test 


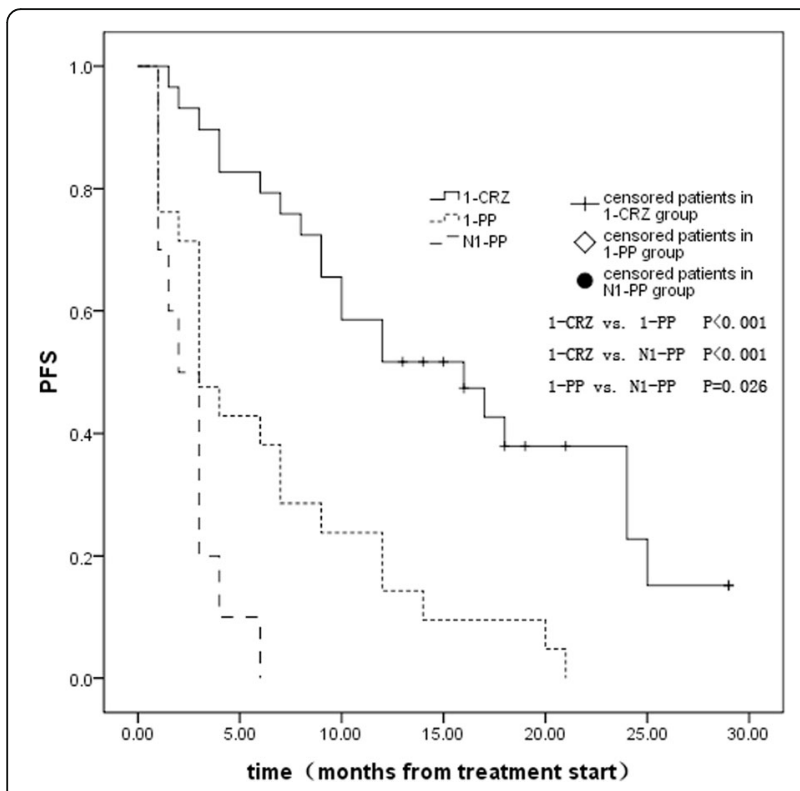

Fig. 1 First-line treatment PFS of patients in the 1-CRZ group, the 1-PP group

to 19.4) and from the 1-PP group (16.2 months, 95\%CI 10.9 to 21.5 ) were both significantly longer than PFS of patients from N1-PP group (8.0 months, $95 \% \mathrm{CI}, 3.3$ to $12.7, P=0.009,0.033$,respectively).

\section{Brain metastasis (BM) in patients received crizotinib treatment}

Among all the 65 crizotinib treated patients, 14 (21.5\%) patients had BM before crizotinib treatment and all received intracranial treatment such as stereotactic radiotherapy (SRT), whole brain radiotherapy (WBRT) or surgeon except one patient. The disease progression

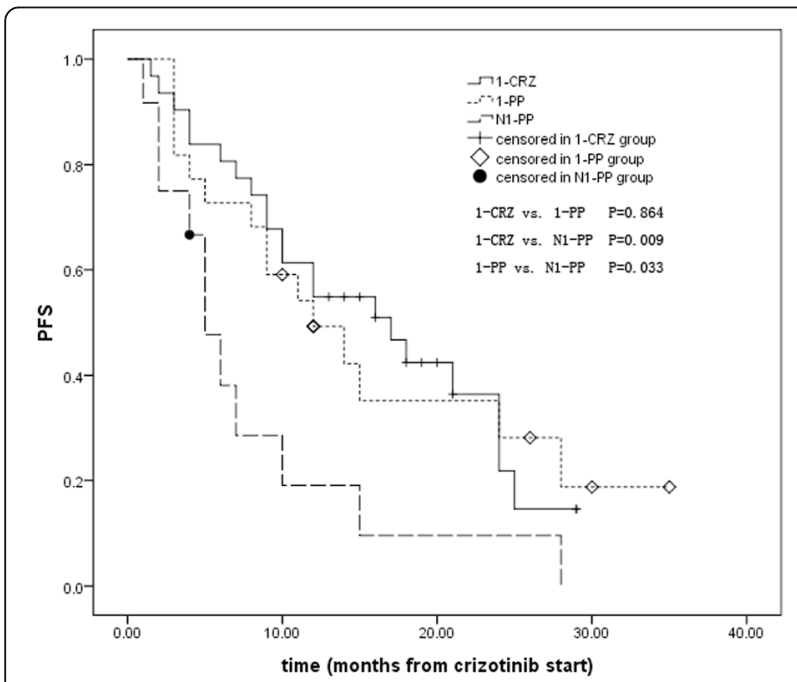

Fig. 2 Crizotinib PFS of patients from the 1-CRZ group, the 1-PP group and the N1-PP group pattern for all patients was shown in Fig. 3. The central nervous system (CNS) was the initial progression site in $22(46.8 \%)$ patients among the 47 patients evaluated $\mathrm{PD}$ at the cut-off date. Patients with BM before crizotinib therapy were more easily present CNS progression $(9 / 14,64.3 \%)$ than patients without BM before crizotinib intake $(13 / 51,25.5 \%, P=0.006)$. The PFS of crizotinib in patients without BM (16.3 months) was longer than in patients with BM before crizotinib treatment (11.6 months), however the difference was not significant $(P=0.123)$.

\section{Multivariate analysis of predictive clinical factors of PFS after crizotinib treatment}

The univariate analysis demonstrated that higher ECOG score $(>=2)$ and patients from N1-PP group had shorter PFS and the result was confirmed by multivariate analysis (Table 4). Higher ECOG score $(>=2)$ was associated with shorter PFS after crizotinib treatment (HR 2.345, 95\% CI 1.137-4.834, $P=0.021$ ). The result was also accordant with PFS analysis, patients with higher ECOG score $(>=2)$ showed shorter PFS (8.5 months) than that of patients with 0 or 1 ECOG score (16.7 months, $P=0.007$ ). Patients received crizotinib after N1-PP chemotherapy were another factors predict shorter PFS than patients received crizotinib after 1-PP chemotherapy or as first-line treatment (HR 2.335, 95\% CI 1.162-4.691, $P=0.017$ ).

Other variables, such as age, smoking history, BM existence before crizotinib, were all not predictive factors of PFS after crizotinib treatment.

\section{Discussion}

Our study compared the efficacy of crizotinib, pemetrexed and other chemotherapy regimens as first line treatments in patients with ALK-positive NSCLC and estimated the efficacy and predictive clinical factors of crizotinib in real world clinical use. Our study indicated the superiority of first line crizotinib treatment over standard chemotherapy in patients with advanced ALKpositive NSCLC as they had a significantly longer PFS and greater DCR and ORR. We also demonstrated that higher ECOG score and received N1-PP chemotherapy before crizotinib were the independent risk factors of short PFS of crizotinib. Patients with BM before crizotinib seemed more easily to occur CNS progression than patients without BM, however, the existence of BM was not related to the PFS of crizotinib in our study.

The efficacy of pemetrexed-based chemotherapy in NSCLC patients with ALK rearrangement was confirmed in several studies, as both a higher response rate and a prolonged PFS were observed $[7,8,14]$. However, the benefit of pemetrexed is less than that of crizotinib, as shown in clinical trials and in our study. The priority of crizotinib as a first-line treatment in our study was 


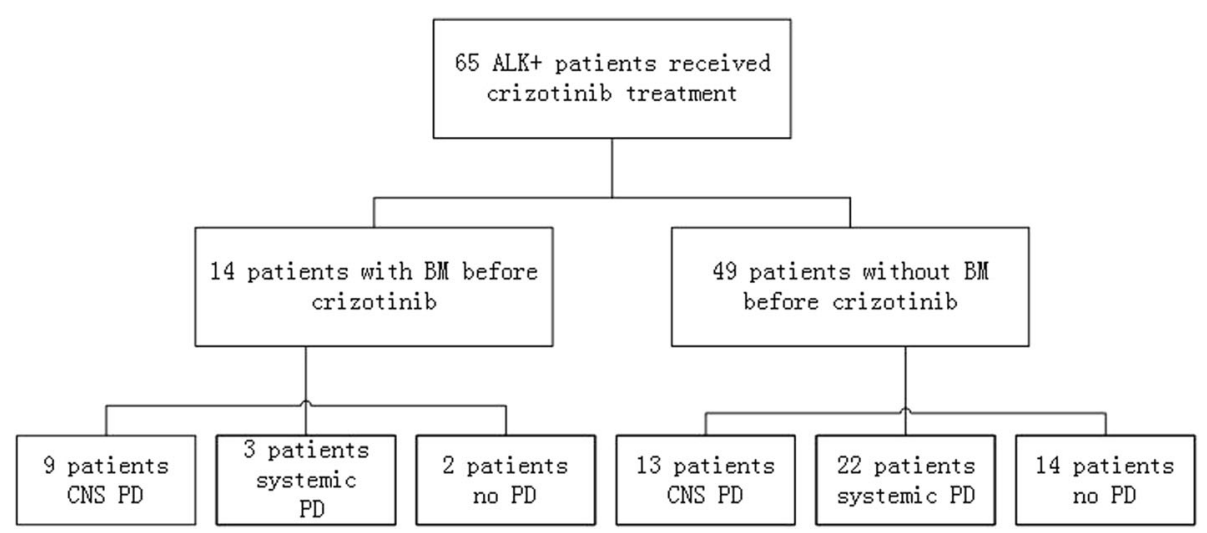

Fig. 3 The disease progression pattern for all patients received crizotinib treatment

consistent with the results of a phase 3 clinical trial [18]. Benjamin et al. [18] reported better efficacy of first-line crizotinib treatment compared with pemetrexed-based chemotherapy (median PFS, 10.9 months vs. 7.0 months; ORR, $74.0 \%$ vs. $45.0 \%$ ) in patients with advanced ALKpositive non-squamous NSCLC who had received no previous systemic treatment.

The efficacy of crizotinib as a first-line setting or after chemotherapy was quite different and the phenomenon was observed in several studies. Camidge et al. [11] revealed that in a phase 1 study, the PFS was 18.3 months in patients $(n=24)$ who received first-line crizotinib treatment and was 9.2 months in patients $(n=125)$ who received crizotinib as a second-line or later treatment. As the results of two phase 3 trials, Benjamin et al. [17] reported that the median PFS of patients who were treated with crizotinib as a first-line treatment was 10.9 months; however, Shaw et al. [13] reported that the PFS was 7.7 months in ALK-positive patients who had received one prior platinum-based regimen. Our study demonstrated the similar result and provided more information about the phenomenon. Patients received crizotinib as a first line treatment or after pemetrexed chemotherapy had a significantly longer crizotinib PFS than patients received crizotinib after non-pemetrexed chemotherapy in our study.

On the whole, 1-PP as first line treatment in ALKpositive patients had a shorter PFS than crizotinib, however, the use of 1-PP did not affect subsequent crizotinib efficacy. N1-PP therapy not only had worse efficacy of the first-line treatment but also affect the subsequent efficacy of crizotinib. Patients after N1-PP usually with worse performance score (ECOG score) might be one reason of the worse efficacy of crizotinib. Our results indicated that crizotinib as a first-line therapy or after pemetrexed chemotherapy in patients who were positive for ALK-rearrangement might have maximized the probability that these patients would benefit from ALKdirected therapy. N1-PP chemotherapy was not recommended for ALK+ NSCLC patients.

CNS progression in ALK rearranged NSCLC patients treated with crizotinib appeared to have a great incidence in patients with or without BM before crizotinib treatment. CNS progression accounted for 46.8\% (22/47) all the PD patients in our study. The incidence was similar with Yoshida et al.'s study $(50 \%, 24 / 48)$ [19]. Poor penetration rate of crizotinib to the cerebrospinal fluid (CSF) may be the the main reason of the great CNS

Table 4 Predictive clinical factors of PFS after crizotinib treatment

\begin{tabular}{llll}
\hline Clinical factors & Univariate analysis & \multicolumn{2}{l}{ Multivariate analysis } \\
\cline { 3 - 4 } & P value & - & $95 \% \mathrm{Cl}$ \\
\hline Gender (male versus female) & 0.318 & - & - \\
Age & 0.175 & - & - \\
Smoking history (smoker versus never smoker) & 0.255 & - & - \\
ECOG score (> = 2 versus 0 or 1) & 0.011 & 2.345 & - \\
TNM stage (IV versus IIIB) & 0.600 & - & - \\
BM status (with versus without BM before crzotinib) & 0.137 & -4.834 \\
First line treatment (N1-PP versus 1-PP or crizotinib) & 0.009 & 2.335 & - \\
\hline Note. CCovariates with a P $\leq$ 0.10 in univariate analysis were included in the multivariate model. Multivariate analysis was performed by using the Cox proportional \\
hazards model
\end{tabular}


progression incidence. Several cases were reported that the crizotinib CSF concentration was very low with a CSF-to-plasma ration of 0.006-0.0026 [20, 21]. Yoshida et al. also reported that there was a significantly shorter median PFS in the BM versus the non-BM patients before crizotinib treatment (median PFS: 6.7 months vs. 10.2 months, $P=0.0347$ ) [19]. In their study, multivariate analysis revealed untreated $\mathrm{BM}$ were associated with the PFS duration (HR 2.314, 95\% CI 1.153-4.400, $P=0.0196)$. Our study also revealed that BM status was significantly associated the occurrence of CNS progression, however, the PFS between patients with and without BM before crizotinib treatment were not significant. We deem it was because most of the patients $(92.9 \%, 13 / 14)$ with $\mathrm{BM}$ in our study received intracranial treatment, such as WBRT or SRT.

\section{Conclusions}

In conclusion, in patients with ALK-positive NSCLC who did not receive previous treatment, crizotinib was superior to standard chemotherapy and was associated with a longer PFS and a greater DCR and ORR. Multivariate analysis revealed that higher ECOG score and received N1-PP chemotherapy before crizotinib were the independent risk factors of short PFS of crizotinib. N1-PP chemotherapy was not recommended for ALK+ NSCLC patients for it not only had shorter PFS as first-line treatment but also affect the subsequent efficacy of crizotinib. Patients with $\mathrm{BM}$ before crizotinib were more easily to occur CNS progression than patients without BM, however, BM after appropriate intracranial therapy was not associated with the PFS of crizotinib.

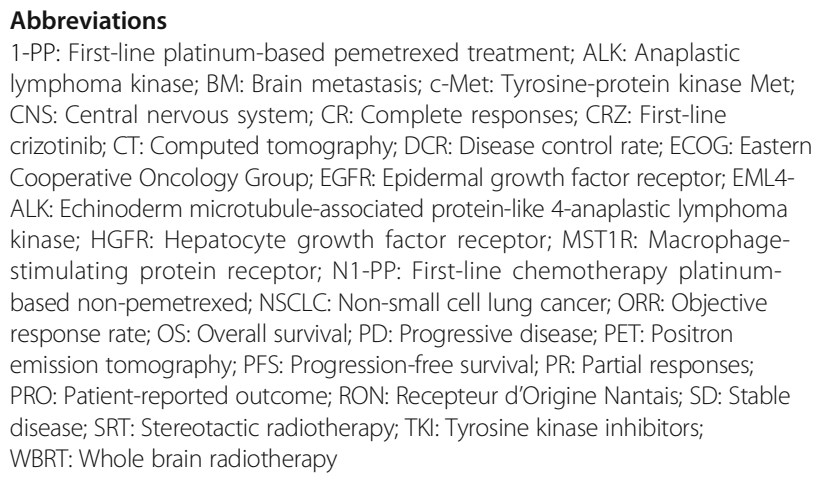

\section{Acknowledgements}

Not applicable

\section{Fundings}

This study has received funding by the National Natural Science Foundation of China (grant number 81472171 and grant number 81672299), the State Scholarship Fund of China(File Number 201308330145) and Project of Health and Family Planning Commission of Zhejiang Province, China (File Number 2017KY058). The funding sources had no role in the study design, data collection, data analysis, or interpretation of the findings.

\section{Availability of data and materials}

Attributing to the privacy of patients, the patient information is publicly inaccessible.

\section{Authors' contributions \\ JYingZ and JYaZ conceived of and carried out the study. JYaZ and JZheng drafted the manuscript,participated in the extraction and analysis of data. XCZ YPZ, QS, YHW, ZYZ, ZJP and YHS participated in the follow-up of patients and extraction of data. JZhao and KS verified,audited the pathology,and took the ALK gene rearrangements Test. All authors read and approved the final manuscript.}

\section{Ethics approval and consent to participate}

Approval for this study was obtained by Ethics Committee of the first affiliated hospital of Zhejiang University and the ethics committee waived the use of the inform consent.

\section{Consent for publication \\ Not applicable}

\section{Competing interests}

The authors declare that they have no competing interests.

\section{Publisher's Note}

Springer Nature remains neutral with regard to jurisdictional claims in published maps and institutional affiliations.

\section{Author details}

${ }^{1}$ Department of Respiratory Disease, Thoracic Disease Center, The First Affiliated Hospital, College of Medicine, Zhejiang University, No. 79, Qingchun Road, Xiacheng District, Hangzhou, China. ${ }^{2}$ Department of Medical Oncology, The First Affiliated Hospital, College of Medicine, Zhejiang University, No. 79, Qingchun Road, Shangcheng District, Hangzhou, China. ${ }^{3}$ Department of Pathology, The First Affiliated Hospital, College of Medicine, Zhejiang University, No. 79, Qingchun Road, Shangcheng District, Hangzhou, China.

Received: 31 December 2016 Accepted: 30 October 2017

Published online: 03 January 2018

\section{References}

1. Siegel R, Naishadham D, Jemal A, et al. Cancer statistics. CA Cancer J Clin. 2012;62(1):10-29.

2. Ettinger DS, Akerley W, Bepler G, Blum MG, Chang A, et al. Non-small cell lung cancer. J Natl Compr Cancer Netw. 2010;8(7):740-801.

3. Wong DW, Leung EL, So KK, Tam IY, Sihoe AD, Cheng LC, Ho KK, Au JS, Chung LP, Pik Wong M. The EML4-ALK fusion gene is involved in various histologic types of lung cancers from nonsmokers with wild-type EGFR and KRAS. Cancer. 2009;115(8):1723-33.

4. Inamura K, Takeuchi K, Togashi Y, Nomura K, Ninomiya H, Okui M, Satoh Y, Okumura S, Nakagawa K, Soda M, Choi YL, Niki T, Mano H, Ishikawa Y. EML4-ALK fusion is linked to histological characteristics in a subset of lung cancers. J Thorac Oncol. 2008;3(1):13-7. https://doi.org/10.1097/JTO. 0b013e31815e8b60.

5. Takahashi T, Sonobe M, Kobayashi M, Yoshizawa A, Menju T, Nakayama E, Mino N, Iwakiri S, Sato K, Miyahara R, Okubo K, Manabe T, Date H. Clinicopathologic features of non-small-cell lung cancer with EML4-ALK fusion gene. Ann Surg Oncol. 2010;17(3):889-97. https://doi.org/10.1245/ s10434-009-0808-7.

6. Fukui T, Yatabe Y, Kobayashi Y, Tomizawa K, Ito S, Hatooka S, Matsuo K, Mitsudomi T. Clinicoradiologic characteristics of patients with lung adenocarcinoma harboring EML4-ALK fusion oncogene. Lung Cancer. 2012; 77(2):319-25. https://doi.org/10.1016/.lungcan.2012.03.013. Epub 2012 Apr 6

7. Camidge DR, Kono SA, Lu X, Okuyama S, Barón AE, Oton AB, Davies AM, Varella-Garcia M, Franklin W, Doebele RC. Anaplastic lymphoma kinase gene arrangement in non-small cell lung cancer are associated with prolonged progression-free survival on pemetrexed. J Thorac Oncol. 2011;6(4):774-80. https://doi.org/10.1097/JTO.0b013e31820cf053.

8. Lee JO, Kim TM, Lee SH, Kim DW, Kim S, Jeon YK, Chung DH, Kim WH, Kim YT, Yang SC, Kim YW, Heo DS, Bang YJ. Anaplastic lymphoma kinase translocation: a predictive biomarker of pemetrexed in patients with non- 
small cell lung cancer. J Thorac Oncol. 2011;6(9):1474-80. https://doi.org/10. 1097/JTO.0b013e3182208fc2.

9. Rodig SJ, Shapiro GI. Crizotinib, a small-molecule dual inhibitor of the c-met and ALK receptor tyrosine kinases. Curr Opin Investig Drugs. 2010;11(12): 1477-90.

10. Cui JJ, Tran-Dubé M, Shen H, Nambu M, Kung PP, Pairish M, Jia L, Meng J, Funk L, Botrous I, McTigue M, Grodsky N, Ryan K, Padrique E, Alton G, Timofeevski S, Yamazaki S, Li Q, Zou H, Christensen J, Mroczkowski B, Bender S, Kania RS, Edwards MP. Structure based drug design of crizotinib (PF-02341066), a potent and selective dual inhibitor of Mesenchymalepithelial transition factor (c-MET) Kinase and Anaplastic lymphoma Kinase (ALK). J Med Chem. 2011;54(18):6342-63.

11. Kwak EL, Bang YJ, Camidge DR, Shaw AT, Solomon B, Maki RG, Ou SH, Dezube BJ, Jänne PA, Costa DB, Varella-Garcia M, Kim WH, Lynch TJ, Fidias P, Stubbs H, Engelman JA, Sequist LV, Tan W, Gandhi L, Mino-Kenudson M, Wei GC, Shreeve SM, Ratain MJ, Settleman J, Christensen JG, Haber DA, Wilner K, Salgia R, Shapiro Gl, Clark JW, lafrate AJ. Anaplastic lymphoma kinase inhibition in non-small-cell lung cancer. N Engl J Med. 2010;363(18): 1693-703. https://doi.org/10.1056/NEJMoa1006448.

12. Camidge DR, Bang YJ, Kwak EL, lafrate AJ, Varella-Garcia M, Fox SB, Riely GJ, Solomon B, Ou SH, Kim DW, Salgia R, Fidias P, Engelman JA, Gandhi L, Jänne PA, Costa DB, Shapiro Gl, Lorusso P, Ruffner K, Stephenson P, Tang Y, Wilner K, Clark JW, Shaw AT. Activity and safety of crizotinib in patients with ALK-positive non-small-cell lung cancer: updated results from a phase 1 study. Lancet Oncol. 2012;13(10):1011-9.

13. Shaw AT, Yeap BY, Solomon BJ, Riely GJ, Gainor J, Engelman JA, Shapiro GI, Costa DB, Ou SH, Butaney M, Salgia R, Maki RG, Varella-Garcia M, Doebele RC, Bang YJ, Kulig K, Selaru P, Tang Y, Wilner KD, Kwak EL, Clark JW, lafrate AJ, Camidge DR. Effect of crizotinib on overall survival in patients with advanced non-small-cell lung cancer harbouring ALK gene rearrangement: a retrospective analysis. Lancet Oncol. 2011;12(11):1004-12.

14. Shaw AT, Kim DW, Nakagawa K, Seto T, Crino L, Ahn MJ, De Pas T, Besse B, Solomon BJ, Blackhall F, Wu YL, Thomas M, O'Byrne KJ, Moro-Sibilot D, Camidge DR, Mok T, Hirsh V, Riely GJ, lyer S, Tassell V, Polli A, Wilner KD, Jänne PA. Crizotinib versus chemotherapy in advanced ALK-positive lung cancer. N Engl J Med. 2013;368(25):2385-94.

15. Sahu A, Prabhash K, Noronha V, Joshi A, Desai S. Crizotinib: a comprehensive review. South Asian J Cancer. 2013;2(2):91-7.

16. Qian H, Gao F, Wang H, Ma F. The efficacy and safety of crizotinib in the treatment of anaplastic lymphoma kinase-positive non-small cell lung cancer: a meta analysis of clinical trials. BMC Cancer. 2014;14:683.

17. Zhou JY, Zheng J, Yu ZF, Xiao WB, Zhao J, Sun K, Wang B, Chen X, Jiang LN, Ding W, Zhou JY. Comparative analysis of clinicoradiologic characteristics of lung adenocarcinomas with ALK rearrangements or EGFR mutations. Eur Radiol. 2015;25(5):1257-66.

18. Solomon BJ, Mok T, Kim D-W, Wu Y-L, Nakagawa K, Mekhail T, Felip E, Cappuzzo F, Paolini J, Usari T, Iyer S, Reisman A, Wilner KD, Tursi J, Blackhall F. First-line crizotinib versus chemotherapy in ALK-positive lung cancer. N Engl J Med. 2014;371(23):2167-77.

19. Yoshida T, Oya Y, Tanaka K, Shimizu J, Horio Y, Kuroda H, Sakao Y, Hida T, Yatabe $Y$. Clinical impact of crizotinib on central nervous system progression inALK-positive non-small lung cancer. Lung Cancer. 2016;97:43-7.

20. Metro G, Lunardi G, Floridi P, Pascali JP, Marcomigni L, Chiari R, Ludovini V, Crinò L, Gori S. CSF concentration of Crizotinib in two ALK-positive nonsmall-cell lung cancer patients with CNSMetastases deriving clinical benefit from treatment. J Thorac Oncol. 2015;10(5):e26-7.

21. Costa DB, Kobayashi S, Pandya SS, Yeo WL, Shen Z, Tan W, Wilner KD. CSF concentration of the anaplastic lymphoma kinase inhibitor crizotinib. J Clin Oncol. 2011;29(15):e443-5.

\section{Submit your next manuscript to BioMed Central and we will help you at every step:}

- We accept pre-submission inquiries

- Our selector tool helps you to find the most relevant journal

- We provide round the clock customer support

- Convenient online submission

- Thorough peer review

- Inclusion in PubMed and all major indexing services

- Maximum visibility for your research

Submit your manuscript at www.biomedcentral.com/submit
() BioMed Central 